\title{
Visual Cortex Activity in Early and Late Blind People
}

\author{
H. Burton \\ Department of Anatomy and Neurobiology, Washington University School of Medicine, St. Louis, Missouri 63110
}

\section{Introduction}

Brain imaging studies describe visual cortex activity in blind people during nonvisual tasks such as Braille reading, hearing words, or sensory discriminations of tactile or auditory stimuli [for literature citations see Burton et al. (2002a,b) and Sadato et al. (2002)]. Simply stated, loss of vision does not lead to permanent inactivation of visual cortex. These counter-intuitive findings support the notion of altered capabilities for surviving modalities through reorganization of cortical functions. There are two possible mechanisms for modifying activity in various parts of visual cortex of blind people. One is that the changes constitute de novo cross-modal plasticity in response to severe unimodal sensory deprivation. The potential processes responsible for novel effects involve anatomical and physiological changes that have been studied extensively using animal models (Bavelier and Neville, 2002). Alternatively, observed access of surviving modalities to deprived cortex is an expression, albeit exaggerated, of normal physiology that usually is inhibited or hidden when vision is present. This potential mechanism relies on possible changes in the balance of activity within existing cortical and subcortical networks. These mechanisms are not mutually exclusive given different ages for blindness onset and, therefore, differences in developmental sensitive periods in establishing connections. Data from brain imaging is especially potent in revealing the network of active cortex. Interpretation of this evidence potentially can reveal which of these mechanisms mostly influences the behavioral adaptations observed in blind people. However, current descriptions of affected visual cortical regions differ, especially regarding whether changes occur early in the hierarchy of visual brain areas, particularly in primary visual cortex (V1), or arise in higher tier areas, some of which normally receive input from other modalities. Some studies report V1 responses in early blind subjects (individuals who were born blind or totally lost sight before age 6) (Sadato et al., 1996, 1998, 2002); other studies indicate $\mathrm{V} 1$ activity mostly in late blind subjects (individuals with sight at birth, who learned to read print, and who lost sight after age 12) (Büchel et al., 1998a,b; Melzer et al., 2001). We observed activity throughout portions of visual cortex in all blind individuals engaged in a Braille reading task, regardless of the age of blindness onset (Burton et al., 2002a). Identification of the possible factors that are responsible for these differing results contributes to consideration of possible mechanisms underlying reorganized activity in visual cortex. Before a discussion of these

This work was supported by National Institutes of Health Grant NS37237. I am especially indebted to all of the blind people who participated in our studies and to Patti Schonlau, a teacher at the Missouri School for the Blind, who recruited these subjects. Vijay Raja contributed to data analyses and preparation of Figure 1. I also thank my colleagues Drs. E. Akbudak, T. Conturo, M. McAvoy, J. Ollinger, M. Raichle, R. Sinclair, A. Snyder, and D. Van Essen for their many contributions.

Correspondence should be addressed to Dr. H. Burton, Department of Anatomy and Neurobiology, Campus Box 8108, Washington University School of Medicine, 660 South Euclid Avenue, St. Louis, M0 63110. E-mail: harold@touch.wustl.edu.

Copyright $\odot 2003$ Society for Neuroscience $\quad$ 0270-6474/03/234005-07\$15.00/0 issues, however, the following briefly summarizes the network of visual cortex responses observed in blind people when they performed a demanding language task.

Subjects in our functional magnetic resonance imaging (fMRI) studies were required to generate a verb to nouns. In one experiment, blind subjects read the nouns through Braille (Braille task) (Burton et al., 2002a); in a second study, blind and sighted subjects heard the nouns (auditory task) (Burton et al., $2002 \mathrm{~b}$ ). The principal finding from both studies was that blind people had activation foci in visual cortex that corresponded to visually responsive regions noted previously in sighted subjects (Malach et al., 1995; Sereno et al., 1995; Tootell et al., 1995, 1996, 1997, 1998; DeYoe et al., 1996; Engel et al., 1997; Hadjikhani et al., 1998). Figure 1 indicates the correspondence between the functional foci in blind people evoked during the verb-generation tasks and visual stimulation-evoked foci in sighted people. This illustration presents results on standardized flat maps from both hemispheres (Van Essen et al., 1998, 2002). The borders of visuotopic areas represent summaries from several studies in which various visual stimuli were presented to sighted people (Tootell et al., 1995, 1997, 1998; Hadjikhani et al., 1998; Van Essen, 2002). The average $z$-score maps are from blind people who generated verbs to nouns read in Braille II (Fig. $1 A$ ) or to heard nouns (Fig. $1 B$ ). These statistical maps summarize results from individual subject analyses. The latter were based on application of a general linear model, an event-related strategy, and an affine transformation of the data from each subject to a standard atlas space (Burton et al., 2002a,b). Except for the anatomical normalization used to align average statistical maps to the coordinate space of the flattened model brain shown in Figure 1, comparable localization of responses was seen in individual subjects.

In early blind subjects, both tasks evoked an extensive bilateral distribution of significant responses throughout currently defined visuotopic areas [V1, V2, V3, V3A, ventral posterior (VP), $\mathrm{V} 4 \mathrm{v}, \mathrm{V} 7, \mathrm{~V} 8$, lateral occipital (LO), and middle temporal area (MT)]; the left hemisphere contained greater activity (Fig. 1). Ventral visual areas $(\mathrm{V} 1 \mathrm{v}, \mathrm{V} 2 \mathrm{v}, \mathrm{VP}$, and V4v) were more responsive, especially during Braille reading (Fig. $1 A$ ). The latter distinction was more evident in the right hemisphere. In V1, V2, V3, VP, and $\mathrm{V} 4 \mathrm{v}$, which display spatially distinctive retinotopic eccentricities in sighted subjects (Tootell et al., 1998), activity in blind subjects was paramount in parafoveal, mostly absent in foveal, and scattered through peripheral representations. The more confined distribution of responses evoked during the Braille task best illustrates this correlation of visual cortex activity in blind people and standard retinotopic maps obtained using visual stimulation and sighted subjects (Fig. 1A). Responses in blind people also occurred throughout the next tier of visual areas (V7, V8, LO, and $\mathrm{MT})$. Activity in the latter regions was bilateral for verb generation with heard nouns (auditory task) and predominated in the left hemisphere with Braille-read nouns.

Late blind people also showed activity in several visual re- 
gions. In contrast to results from early blind subjects, responses were greater in the right hemisphere for the Braille task (Fig. $1 A$ ) and in the right V1v for the auditory task. However, right hemispheredominant responses were elicited only during the Braille task for higher visual areas. Striking was that responses were more confined to parafoveal parts of affected visual areas. The right hemisphere in both studies, for example, contained activity near the centers of V1d, V1v, V2d, V2v, $\mathrm{V} 3, \mathrm{VP}, \mathrm{V} 3 \mathrm{~A}$, and V4v. A similar pattern occurred throughout the same regions in the left hemisphere for the auditory task. Small responses were also concentrated in parafoveal parts of dorsal and ventral V1 and V2 in the left hemisphere during the Braille task. With the exception of V8, and possibly LO, higher tier visual areas showed little activity in these subjects.

Activity occurred in late blind, although most had no previous visual deficits before blindness. All but one late blind subject had absolutely no light sensitivity. The average age of blindness onset for the studied population was beyond sensitive periods even for slowly maturing visual cortex functions (Kovacs, 2000). In the study with heard nouns, the average age was $>19$ years (range $7-36$ years) (Burton et al., 2002a), and in the study with Brailleread nouns, it was $>12$ years (range $10-25$ years) (Burton et al., 2002b). Thus, in contrast to the early blind subjects, visual cortex had time to develop normally because even the youngest late blind subject was older than the sensitive period for most synapse elimination [see references cited in Bavelier and Neville (2002)]. Although these subjects showed less responsiveness, they nevertheless exhibited comparable visual cortex involvement. In contrast, the population of studied sighted subjects showed no significant visual cortex activity during the auditory task (Burton et al., 2002b).

These results attest to a robust capacity for cortical reorganization subsequent to unimodal sensory deprivation. The striking effects involve increased responsiveness to the spared modalities of touch and hearing in the visual cortical regions deprived of vision. It is probable that unanticipated cross-modal responses noted in visual cortex of blind people reflect a more general phenomenon. Thus, primary [Brodmann area (BA) 41] and higher level (BA 42 and 22) auditory cortices in deaf people respond to visual stimulation (Finney et al., 2001; Bavelier and Neville, 2002), which indicates that any severe unimodal deafferentation precipitates unexpected sensory access to the affected cortex. There is much debate on the mechanisms responsible for such examples of cross-modal plasticity (Bavelier and Neville, 2002). Brain imaging studies especially demonstrate that cross-modal alterations evidently persist throughout life because late and early blind subjects show some comparable changes. However, the re- organizations noted in these two populations are not identical, which indicates that maturation and behavioral experience can influence which brain areas retain adaptive potential. The following discussion examines mechanisms and conditions possibly responsible for enhanced processing of remaining modalities in deprived visual cortex.

One might explain all visual cortex responses in blind people as an epiphenomenon with no functional role because the activity reflects nonspecific, excess excitability subsequent to sensory deprivation. Evidence of higher than normal glucose metabolism in early blind visual cortex (Wanet-Defalque et al., 1988; De Volder et al., 1997) is suggestive of possible instability in sensorydeprived cortex. This idea mostly applies to individuals whose total lack of visual experience might induce abnormal responses (Snyder and Shapley, 1979) because exuberant excitatory connections are not pruned (Röder et al., 1997). Several findings 
indicate that an explanation of nonfunctional hyperexcitability is unlikely for data such as that shown in Figure 1.

Contrary to an expectation of instability, visual cortex in blind people does not exhibit lower excitability thresholds to transcranial magnetic stimulation (TMS). Thus, similar TMS levels evoke visual experience of phosphenes when applied over occipital cortex in some congenitally blind people, those who are blind but retain some light or motion sensitivity, and sighted subjects (Gothe et al., 2002). However, TMS to occipital cortex elicits no phosphenes in most early blind subjects who have no previous visual function (Gothe et al., 2002). Nevertheless, another study demonstrated interference with Braille reading when TMS was applied to occipital visual areas in early blind subjects (Cohen et al., 1997, 1999), which indicates that occipital cortex contributes some function in these people.

It is unlikely that responses in visual cortex are nonspecific because activity domains in many visual areas predominantly occupied confined parafoveal parts of retinotopic maps. In sighted subjects, focal activity patterns to visual stimulation generally constitute proof of restricted, and likely specific, functions. Thus, similarly localized activity in blind people possibly represents specific excitability. This is a parsimonious idea, even without knowing precise functions for the responses. Only higher tier visual regions like V7, V8, MT, and possibly LO exhibited fewer focal activity patterns in blind subjects. However, retinotopic organization in these regions is less precise in sighted subjects, which might explain the more widespread pattern of responses seen when these regions are activated in blind people. Additional regional specificity was evident in the relative dominance of responses in the left hemisphere, which also varied with verb generation to Braille-read or heard nouns.

A likely basis for the extensive visual cortex responses to heard nouns is a general sensitivity to various non-language-related auditory stimuli in early (Kujala et al., 1995a,b, 1997; Röder et al., 1996, 2000, 2001; Lessard et al., 1998; Liotti et al., 1998; Leclerc et al., 2000; Weeks et al., 2000; Arno et al., 2001) and late blind (Kujala et al., 2000) individuals. A PET study, for example, showed V1 activity in early blind subjects during a soundlocalization task (Weeks et al., 2000). Of particular relevance to the question of whether cross-modal responses serve an adaptive function is that several studies demonstrated superior performance by blind people when the tasks involved selective attention to some attribute of the auditory stimulation. Examples included detecting a deviant frequency (Kujala et al., 1995b), a particular tone in one ear with distracting sounds in the other ear (Liotti et al., 1998), and attending to a specific azimuth domain in a binaural sound localization task (Leclerc et al., 2000). The enhanced behavioral performance presumably reflects compensatory adaptations to loss of sight (Röder et al., 2001; Zatorre, 2001). A possible mechanism is likely coupled to the presence of visual cortex activation by auditory stimuli in blind people.

A plausible explanation for the results involving Braille reading is that visual cortex adapts by acquiring a capacity to process tactile stimuli. Consistent with this are PET studies that described V1 and adjacent visual cortex responses when early blind subjects actively explored and discriminated between Braille-like stimuli (Sadato et al., 1996, 1998). These experiments confounded sensory and motor processes because subjects haptically explored the tactile stimuli. A subsequent fMRI study confirmed that tactile stimulus activation of visual cortex correlated with sensory processing because tactile discrimination was of passively applied Braille-like stimuli (Sadato et al., 2002). Most evident were responses in early blind subjects who lost sight between $<1-15$ years of age (average $<6$ years). Late blind subjects (age range at onset of blindness: $20-51$ years, average 33 years) showed little to no activity in V1 and adjacent regions (Sadato et al., 2002). This supports earlier negative findings of no TMS-induced disruption in Braille reading in late blind people (Cohen et al., 1999). These differences correlate with the age of blindness onset and suggest a limited sensitive period for adapting visual cortex to process tactile stimuli (Sadato et al., 2002).

Several issues caution categorically concluding that late blind people lack neural plasticity comparable with that observed in people with $>12$ years age of blindness onset. First, having any visual stimulus sensitivity might prevent novel adaptations. Thus, sighted subjects show no responses in visual cortex during simple tactile matching tasks, but five of six late blind subjects in the study by Sadato and colleagues (Sadato et al., 2002) had some binocular visual sensitivity to light or hand movements or both. This retained visual function might have inhibited adaptive changes to nonvisual modalities in the studied late blind population. Second, performance by the late blind subjects was nearly at chance levels and contrasted with the $>75 \%$ correct discriminations by the early blind. Absence of visual cortex responses in late blind subjects therefore might reflect unequal performance in contrast to inadequate neural plasticity. Finally, Sadato and colleagues (2002) used an analysis that potentially lacked sensitivity if hemodynamic responses in late blind differed from those in early blind subjects. Their analysis incorporated a hemodynamic response model into the design matrix as a regressor, which could have reduced computed response magnitudes if hemodynamic responses in late blind subjects had different delays (Ollinger et al., 2001). The results shown in Figure 1 relied on an event-related analysis wherein time courses were estimated and subsequently correlated with assumed hemodynamic responses. These methods revealed V1 and higher tier visual cortex activity in individual late blind subjects (Burton et al., 2002a,b).

Given tactile stimulus activation of visual cortex, previously demonstrated responses in the same cortical regions during Braille reading possibly reflect analyzing orthographic features associated with Braille cell tactile shapes (Melzer et al., 2001; Burton et al., 2002a). This interpretation implies that visual cortex activity represents the processing of Braille orthography as though it were print. Consistent with this interpretation are PET studies by Büchel and colleagues (1998a,b), whose subjects had to detect whether any Braille cell in a word or consonant string included an elevated dot 6 . This task required processing Braille cell shape. They reported responses in V1 and higher visual areas only in late blind subjects and in extrastriate regions in early blind subjects (Büchel et al., 1998a). The dot-detection task used in this study may have inadvertently favored activation in late blind subjects who attend more frequently to Braille cell shape when reading (Millar, 1997). This focus on Braille cell spatial patterns possibly derives from previous visual experience in late blind individuals who, for similar reasons, are more adept in tactile picture recognition tasks (Heller, 1989). When tactile discrimination tasks do not invoke previous visual experience, late blind subjects show no advantage and hence show diminished activity in V1 (Sadato et al., 2002).

Several findings indicate limited explanatory value to the hypothesis that visual cortex activity in blind people demonstrates just an adaptation to processing tactile stimuli and hence Braille orthography. First, the cortical network for orthography in blind people is potentially comparable with the wide network recognized in sighted subjects (Tagamets et al., 2000) and therefore unlikely to be confined to visual cortex. Another important com- 
ponent of this skepticism is that in blind people Braille orthography recedes in significance with increased reading fluency (Millar, 1987, 1997; Davidson et al., 1992; Loomis, 1993). Braille reading fluency and visual cortex activity might then be expected to relate indirectly. In contrast, early blind subjects, who usually read Braille better than late blind individuals, have greater activity in visual cortex (Fig. 1A) (Burton et al., 2002a). These results contradict the idea that processing Braille orthography is a necessary component of visual cortex responses in early blind people.

An alternative interpretation is that visual cortex activity indicates language processes. Two reports consistent with this idea show dissociations between tactile perceptions of Braille fields (i.e., Braille orthography) and literacy for the same object in early blind subjects. A TMS experiment indicated that tactile stimulation associated with Braille reading recruits somatosensory cortex first. This study showed that TMS over parietal cortex $20 \mathrm{msec}$ after a Braille stimulus presentation interfered with stimulus detection, but TMS over occipital cortex blocked discrimination, but not detection, of Braille letters only after a longer delay of 50-80 msec (Hamilton and Pascual-Leone, 1998). These results suggest that activity in parietal cortex must precede the processes underlying letter recognition in occipital cortex. A similar dissociation between tactile sensations and Braille literacy was reported in an early blind individual who suffered a bilateral occipital ischemic stroke. This patient subsequently detected tactile stimulation associated with touching Braille fields but could not read them (Hamilton et al., 2000). Deficient Braille literacy in both instances might reflect disrupted language processes operating in occipital cortex. However, the results might still be interpretable as disrupted processing of Braille orthography.

Visual cortex responses in blind people ostensibly indicate language mechanisms normally hidden by visual stimulation effects of print in sighted subjects. A verb-generation task involves obligatory semantic analyses of read and generated words (Gabrieli et al., 1998; Seger et al., 1999); this lexical process possibly evoked activity in early and late blind subjects in V1 and multiple higher visual cortex areas in the auditory task in which Braille reading was absent (Burton et al., 2002b). Similar positive findings for V1 responses in a PET study by Sadato and colleagues (Sadato et al., 1996, 1998) might have resulted from implicit semantic processing when subjects read Braille words (Gabrieli et al., 1998). Furthermore, left hemisphere dominance of most activity, especially in early blind subjects, indicates that visual cortex in blind people follows a left preference that is usual for many language processes (Geschwind and Galaburda, 1985; Petersen et al., 1990; Petersen and Fiez, 1993; Petitto et al., 2000).

The visual cortex responses elicited by verb generation to heard words provide suggestive evidence of language processes. We hypothesize that in Braille-literate blind people, heard words might be associatively linked to encoded Braille (Burton et al., 2002b) because learning Braille after blindness requires prolonged practice in connecting the feel of Braille fields and phonics (Nolan and Kederis, 1969; Pring, 1985, 1994; Millar, 1997). The latter attach lexical meaning to the tactile sensations. It is possible, therefore, that Braille literacy is a lexical rather than primarily a haptic skill. Given the evidence of visual cortex activity, we speculate that this lexical processor partly exists in left visual cortex. Through prolonged associations, the lexical processor in visual cortex responds to heard words. The alternative argument is that visual cortex responds independently to auditory and tactile stimulation. Again, however, through associative coupling in learning Braille, these two modalities become linked in a lexical processor, which leads to the stronger and more extensive activa- tion of visual cortex noted to heard words (Fig. 1). This hypothesis implies that rehabilitation supporting Braille literacy positively influences language processes in visual cortex for listening and reading words.

Common, multimodal representations in the brain provide an important potential mechanism that is responsible for visual cortex activity in blind people. Brain imaging data like that shown in Figure 1 indicate substantial activation of several extrastriate regions with known multimodal responses (see below). Thus, processes expressed in regions where representations from different modalities converge activate multiple visual areas and might support the abilities of blind people to read Braille, perform language tasks to heard words, and execute various tactile or auditory discrimination tasks that depend on some spatial knowledge. Multimodal regions with cortical connections to lower tier somatosensory, auditory, and visual representations occur in posterior parietal, superior and middle temporal, and several extrastriate regions (Andersen et al., 1990; Felleman and Van Essen, 1991; Lewis and Van Essen, 2000; Falchier et al., 2002). A potential consequence of visual deprivation might be alteration of the dominant flow of interactive controls through cortical connections linking different levels of visual cortex. One possibility is that activity in multimodal extrastriate regions provides stronger than normal top-down influences on lower tier visual areas such as V1 (Sadato et al., 2002). Some of these effects might reflect the topography of cortical connections. For example, Falchier and colleagues (2002) reported in monkeys that core and neighboring auditory and multimodal temporal regions preferentially connect to V1 visual field representations at an eccentricity of 10$20^{\circ}$. The absence of direct projections to foveal representations in V1 parallels the lack of responses at this eccentricity shown in Figure 1 for both verb-generation tasks. These correlated findings emphasize how existing connections, the normal purpose of which is likely multimodal integration even at the earliest stages of visual processing, might influence activity in blind people.

The idea that extrastriate visual areas are a possible source of changes noted in blind people must consider evidence that these regions normally contribute to performance of tactile tasks in sighted individuals. Several studies with sighted subjects show that selected tactile discriminations use visual processes in extrastriate visual areas. A PET study reported responses in portions of occipital-parietal visual cortex (BA 19) when sighted subjects discriminated differences in the orientation of tactile gratings (Sathian and Zangaladze, 2001). TMS aimed at this region disrupted discrimination of different grating orientations but not spacings between tactile stimuli (Zangaladze et al., 1999). Sathian and colleagues (Sathian and Zangaladze, 2001) suggested that perceptions of tactile grating orientation required spatial mental imagery that is uniquely served by orientation-selective neurons located in these extrastriate visual regions. Another study (De Volder et al., 2001) identified foci in ventral visual regions, especially in the left posterior fusiform gyrus (BA 19/37) and posterior inferotemporal gyrus (BA 37), when sighted and early blind subjects mentally imagined object shapes that were first recognized from normally associated totem sounds or from haptic exploration. These findings illustrate cross-modal perceptual representations in the absence of vision. All active regions in these studies, however, occupied relatively higher tier extrastriate cortex.

On a broader level, these studies involving multimodal extrastriate regions have invoked mechanisms for mental imagery (Büchel et al., 1998a,b; Mellet et al., 2000; De Volder et al., 2001; Sathian and Zangaladze, 2001). Implied is that responses on the basis of mental imagery in blind people substantiate "visualiza- 
tion" of Braille fields or heard words in auditory language tasks. The suggestion that the consequences of these events in extrastriate regions flow down to lower tier visual areas like V1 (Sadato et al., 2002) omits the possibility of direct involvement of V1 in mental imagery tasks (Kosslyn et al., 1995, 2001; Thompson et al., 2001). The latter might explain how mental imagery mechanisms apply to late blind subjects who show less activity in the multimodal extrastriate regions.

Any hypothesis based on brain regions responsible for mental imagery does not fully explain the contradiction in early blind people, who have the least experience with objects yet have the greatest extent of activity in cortical areas involved in visual imagery. Despite some experience-based superiority in performing some tactile discrimination tasks (Stevens et al., 1996; Grant et al., 2000; Van Boven et al., 2000), early blind people are also less adept at tasks requiring mental rotation of tactile stimuli (Sathian, 2000) or visuospatial and pictorial imagery (Aleman et al., 2001). These deficits might indicate limitations imposed by haptic experience when the tactile modality is the only sense available to cross-modal visual areas responsible for mental imagery (Aleman et al., 2001). It is therefore incongruous to suggest that early blind subjects "mentally visualized" Braille fields or heard nouns when doing verb generation because only these subjects showed activity in the appropriate extrastriate cortical regions. It is also implausible that verb generation in some blind people arises from mental imagery when sighted and late blind subjects do the same task to heard nouns without activating comparable extrastriate regions.

Some studies alternatively interpret extrastriate visual cortex activity in blind people as representing normal object recognition, which likely engages mental imagery processes, however. In sighted people, LO is particularly active during multimodal object recognition tasks (Malach et al., 1995; Amedi et al., 2001; Grill-Spector et al., 2001). LO and regions in the anterior fusiform and inferior temporal gyri also respond during tactile object recognitions in blind people (Büchel et al., 1998b). An fMRI study with sighted subjects and a tactile object recognition task identified a network of cortical areas that included responses in V1 (Deibert et al., 1999). An interpretation of object recognition processes is partially applicable to results from early blind people. Thus, Braille fields are putatively perceived as objects, especially in fluent readers who conceptualize whole words (Krueger, 1982). We previously also hypothesized that through haptic exploration, Braille fields elicit perceptual projections into the object space of each Braille cell pattern (Burton et al., 2002a). Although attractive, an object recognition hypothesis has limited explanatory power because comparable extrastriate regions are not seen in sighted or late blind subjects when they perform the same tasks.

Much of what has been discussed is by necessity speculative because of inadequate understanding of how severe unimodal sensory deprivation affects all of the cortical areas normally activated by vision. Brain imaging studies have revealed the extent of visual cortical reorganization in blind people and have highlighted some potential processes responsible for these changes. However, concluding that visual cortex activity in blind people represents evidence of cortical reorganization raises questions about whether these results express normal processes found in sighted people, like mental imagery, or indicate neural plasticity precipitated by severe sensory deprivation. A necessary aspect of considering visual cortex activity in blind people as evidence of neural plasticity is identification of mechanism(s) and processes responsible for novel cross-modal activity. Structural and neurodevelopment factors such as preservation of transient cross- modal connections from tactile and auditory thalamic centers to visual cortex, alterations in transient intracortical connections, and preservation of multimodal neurons in primary sensory cortical areas are examples of issues best studied in animals (Bavelier and Neville, 2002). Although many of these processes potentially apply to early blind people, they have minimal application to the more varied results noted in late blind people. These people also have a more variable experience with sensory deprivation that has sometimes been ignored in making comparisons with results from early blind people. Behavioral variables such as previous and retained visual experience, practice, equivalent performance success, and lexical processes (i.e., orthography, phonology, syntactics, and semantics) are all factors that have received less study. Enhancements or deficits in these behavioral variables and interactions between the factors are likely to be complex. A better understanding of cross-modal effects will depend on future studies that control and understand these interactions. This approach will potentially illuminate mechanisms underlying distinguishing patterns of brain activity in late and early blind people.

These unanticipated findings on visual cortex activity in blind people would not be available with such extensive detail without brain imaging technology. There are several crucial and unique aspects to the knowledge obtained through these studies. Especially important has been the close association between spatially distributed statistical assessments of brain activity and whole brain anatomy. This standardization of data analyses through brain anatomy has been critically permissive in allowing comparisons across diverse studies. Because $\mathrm{fMRI}$ is noninvasive, there is no harm in repeatedly studying the same subjects. In this way, subtle alterations in experimental design can be used to tease apart differences in activity patterns and thereby elucidate potential mechanisms for dynamic changes in brain activity such as those seen in blind people. Another valuable consideration is that these are human studies. As a consequence, we have been able to examine language processes as a possible underlying functional basis for the observed visual cortex activity in blind people. Comparisons between visual versus nonvisual causes of responses in comparable visual cortex regions in sighted and blind people, respectively, have expanded appreciation of a very dynamic and malleable network the primordial responsiveness of which can change rather than simply disappear after sensory deprivation. Furthermore, a conception of visual cortex functions that depend solely on analyses of single neuron firing patterns in animals is too restrictive, especially because BOLD responses represent a broader spectrum of neurophysiological activity (Logothetis and Lauritzen, 2003). Perhaps of utmost importance to brain imaging studies, however, have been perspectives based on examining results across specific anatomical structures throughout the whole brain, which is a view rarely possible with other technologies. Although not discussed above, we have noted, for example, that frontal cortex language areas in blind people exhibit a network identical to that observed in sighted individuals performing verb generation (Burton et al., 2002a,b). This observation therefore accentuates visual cortex as the main setting for neuroplasticity in these people.

\section{References}

Aleman A, van Lee L, Mantione MH, Verkoijen IG, de Haan EH (2001) Visual imagery without visual experience: evidence from congenitally totally blind people. NeuroReport 12:2601-2604.

Amedi A, Malach R, Hendler T, Peled S, Zohary E (2001) Visuo-haptic objectrelated activation in the ventral visual pathway. Nat Neurosci 4:324-330.

Andersen RA, Asanuma C, Essick G, Siegel RM (1990) Corticocortical connections of anatomically and physiologically defined subdivisions within the inferior parietal lobule. J Comp Neurol 296:65-113. 
Arno P, De Volder AG, Vanlierde A, Wanet-Defalque MC, Streel E, Robert A, Sanabria-Bohorquez S, Veraart C (2001) Occipital activation by pattern recognition in the early blind using auditory substitution for vision. NeuroImage 13:632-645.

Bavelier D, Neville HJ (2002) Cross-modal plasticity: where and how? Nat Rev Neurosci 3:443-452.

Büchel C, Price C, Frackowiak RS, Friston K (1998a) Different activation patterns in the visual cortex of late and congenitally blind subjects. Brain 121:409-419.

Büchel C, Price C, Friston K (1998b) A multimodal language region in the ventral visual pathway. Nature 394:274-277.

Burton H, Snyder AZ, Conturo TE, Akbudak E, Ollinger JM, Raichle ME (2002a) Adaptive changes in early and late blind: a fMRI study of Braille reading. J Neurophysiol 87:589-611.

Burton H, Snyder AZ, Diamond J, Raichle ME (2002b) Adaptive changes in early and late blind: a fMRI study of verb generation to heard nouns. J Neurophysiol 88:3359-3371.

Cohen LG, Celnik P, Pascual-Leone A, Corwell B, Faiz L, Dambrosia J, Honda M, Sadato N, Gerloff C, Catala MD, Hallett M (1997) Functional relevance of cross-modal plasticity in blind humans. Nature 389:180-183.

Cohen LG, Weeks RA, Sadato N, Celnik P, Ishii K, Hallett M (1999) Period of susceptibility for cross-modal plasticity in the blind. Ann Neurol 45:451-460.

Davidson PW, Appelle S, Haber RN (1992) Haptic scanning of Braille cells by low- and high-proficiency blind readers. Res Dev Disabil 13:99-111.

Deibert E, Kraut M, Kremen S, Hart J Jr (1999) Neural pathways in tactile object recognition. Neurology 52:1413-1417.

De Volder AG, Bol A, Blin J, Robert A, Arno P, Grandin C, Michel C, Veraart C (1997) Brain energy metabolism in early blind subjects: neural activity in the visual cortex. Brain Res 750:235-244.

De Volder AG, Toyama H, Kimura Y, Kiyosawa M, Nakano H, Vanlierde A, Wanet-Defalque MC, Mishina M, Oda K, Ishiwata K, Senda M (2001) Auditory triggered mental imagery of shape involves visual association areas in early blind humans. NeuroImage 14:129-139.

DeYoe EA, Carman GJ, Bandettini P, Glickman S, Wieser J, Cox R, Miller D, Neitz J (1996) Mapping striate and extrastriate visual areas in human cerebral cortex. Proc Natl Acad Sci USA 93:2382-2386.

Engel SA, Glover GH, Wandell BA (1997) Retinotopic organization in human visual cortex and the spatial precision of functional MRI. Cereb Cortex 7:181-192.

Falchier A, Clavagnier S, Barone P, Kennedy H (2002) Anatomical evidence of multimodal integration in primate striate cortex. J Neurosci 22:5749-5759.

Felleman DJ, Van Essen DC (1991) Distributed hierarchical processing in the primate cerebral cortex. Cereb Cortex 1:1-47.

Finney EM, Fine I, Dobkins KR (2001) Visual stimuli activate auditory cortex in the deaf. Nat Neurosci 4:1171-1173.

Gabrieli JD, Poldrack RA, Desmond JE (1998) The role of left prefrontal cortex in language and memory. Proc Natl Acad Sci USA 95:906-913.

Geschwind N, Galaburda AM (1985) Cerebral lateralization. Biological mechanisms, associations, and pathology: III. A hypothesis and a program for research. Arch Neurol 42:634-654.

Gothe J, Brandt SA, Irlbacher K, Roricht S, Sabel BA, Meyer BU (2002) Changes in visual cortex excitability in blind subjects as demonstrated by transcranial magnetic stimulation. Brain 125:479-490.

Grant AC, Thiagarajah MC, Sathian K (2000) Tactile perception in blind Braille readers: a psychophysical study of acuity and hyperacuity using gratings and dot patterns. Percept Psychophys 62:301-312.

Grill-Spector K, Kourtzi Z, Kanwisher N (2001) The lateral occipital complex and its role in object recognition. Vision Res 41:1409-1422.

Hadjikhani N, Liu AK, Dale AM, Cavanagh P, Tootell RB (1998) Retinotopy and color sensitivity in human visual cortical area V8. Nat Neurosci 1:235-241.

Hamilton R, Keenan JP, Catala M, Pascual-Leone A (2000) Alexia for Braille following bilateral occipital stroke in an early blind woman. NeuroReport 11:237-240

Hamilton RH, Pascual-Leone A (1998) Cortical plasticity associated with Braille learning. Trends Cogn Sci 2:168-174.

Heller MA (1989) Picture and pattern perception in the sighted and the blind: the advantage of the late blind. Perception 18:379-389.

Kosslyn SM, Thompson WL, Kim IJ, Alpert NM (1995) Topographical representations of mental images in primary visual cortex. Nature 378:496-498.
Kosslyn SM, Ganis G, Thompson WL (2001) Neural foundations of imagery. Nat Rev Neurosci 2:635-642.

Kovacs I (2000) Human development of perceptual organization. Vision Res 40:1301-1310.

Krueger LE (1982) A word-superiority effect with print and Braille characters. Percept Psychophys 31:345-352.

Kujala T, Alho K, Kekoni J, Hamalainen H, Reinikainen K, Salonen O, Standertskjold-Nordenstam CG, Naatanen R (1995a) Auditory and somatosensory event-related brain potentials in early blind humans. Exp Brain Res 104:519-526.

Kujala T, Huotilainen M, Sinkkonen J, Ahonen A, Alho K, Hamalainen M, Ilmoniemi R, Kajola M, Knuutila J, Lavikainen J, Salonen O, Simola J, Standerskjold-Nordenstam C-G, Tiitinen H, Tissari S, Naatanen R (1995b) Visual cortex activation in blind humans during sound discrimination. Neurosci Lett 183:143-146.

Kujala T, Alho K, Huotilainen M, Ilmoniemi RJ, Lehtokoski A, Leinonen A, Rinne T, Salonen O, Sinkkonen J, Standertskjold-Nordenstam CG, Naatanen R (1997) Electrophysiological evidence for cross-modal plasticity in humans with early- and late-onset blindness. Psychophysiology 34:213-216.

Kujala T, Alho K, Naatanen R (2000) Cross-modal reorganization of human cortical functions. Trends Neurosci 23:115-120.

Lauritzen M, Gold L (2003) Brain function and neurophysiological correlates of signals used in functional neuroimaging. J Neurosci 23:3969-3977.

Leclerc C, Saint-Amour D, Lavoie ME, Lassonde M, Lepore F (2000) Brain functional reorganization in early blind humans revealed by auditory event-related potentials. NeuroReport 11:545-550.

Lessard N, Paré M, Lassonde M (1998) Early-blind human subjects localize sound sources better than sighted subjects. Nature 395:278-280.

Lewis JW, Van Essen DC (2000) Corticocortical connections of visual, sensorimotor, and multimodal processing areas in the parietal lobe of the macaque monkey. J Comp Neurol 428:112-137.

Liotti M, Ryder K, Woldorff MG (1998) Auditory attention in the congenitally blind: where, when and what gets reorganized? NeuroReport 9:1007-1012.

Logothetis NK (2003) The underpinnings of the BOLD fMRI signal. J Neurosci 23:3963-3968.

Loomis JM (1993) Counterexample to the hypothesis of functional similarity between tactile and visual pattern perception. Percept Psychophys 54:179-184.

Malach R, Reppas JB, Benson RR, Kwong KK, Jiang H, Kennedy WA, Ledden PJ, Brady TJ, Rosen BR, Tootell RB (1995) Object-related activity revealed by functional magnetic resonance imaging in human occipital cortex. Proc Natl Acad Sci USA 92:8135-8139.

Mellet E, Tzourio-Mazoyer N, Bricogne S, Mazoyer B, Kosslyn SM, Denis M (2000) Functional anatomy of high-resolution visual mental imagery. J Cogn Neurosci 12:98-109.

Melzer P, Morgan VL, Pickens DR, Price RR, Wall RS, Ebner FF (2001) Cortical activation during Braille reading is influenced by early visual experience in subjects with severe visual disability: a correlational fMRI study. Hum Brain Mapp 14:186-195.

Millar S (1987) Perceptual and task factors in fluent Braille. Perception 16:521-536.

Millar S (1997) Reading by touch. London: Routledge.

Nolan C, Kederis C (1969) Perceptual factors in Braille word recognition. New York: American Foundation for the Blind.

Ollinger JM, Corbetta M, Shulman GL (2001) Separating processes within a trial in event-related functional MRI II. Analysis. NeuroImage 13:218-229.

Petersen S, Fiez J (1993) The processing of single words studied with positron emission tomography. Annu Rev Neurosci 16:509-530.

Petersen SE, Fox PT, Snyder AZ, Raichle ME (1990) Activation of extrastriate and frontal cortical areas by visual words and word-like stimuli. Science 249:1041-1044.

Petitto LA, Zatorre RJ, Gauna K, Nikelski EJ, Dostie D, Evans AC (2000) Speech-like cerebral activity in profoundly deaf people processing signed languages: implications for the neural basis of human language. Proc Natl Acad Sci USA 97:13961-13966.

Pring L (1985) Processes involved in Braille reading. J Visual Impair Blind 79:252-255.

Pring L (1994) Touch and go: learning to read Braille. Read Res Quart 29:67-74.

Röder B, Rösler F, Hennighausen E, Näcker F (1996) Event-related potentials during auditory and somatosensory discrimination in sighted and blind human subjects. Cognit Brain Res 4:77-93. 
Röder B, Rösler F, Hennighausen E (1997) Different cortical activation patterns in blind and sighted humans during encoding and transformation of haptic images. Psychophysiology 34:292-307.

Röder B, Rösler F, Neville HJ (2000) Event-related potentials during auditory language processing in congenitally blind and sighted people. Neuropsychologia 38:1482-1502.

Röder B, Rösler F, Neville HJ (2001) Auditory memory in congenitally blind adults: a behavioral-electrophysiological investigation. Cognit Brain Res 11:289-303.

Sadato N, Pascual-Leone A, Grafman J, Ibanez V, Deiber MP, Dold G, Hallett M (1996) Activation of the primary visual cortex by Braille reading in blind subjects. Nature 380:526-528.

Sadato N, Pascual-Leone A, Grafman J, Deiber MP, Ibanez V, Hallett M (1998) Neural networks for Braille reading by the blind. Brain 121:1213-1229.

Sadato N, Okada T, Honda M, Yonekura Y (2002) Critical period for crossmodal plasticity in blind humans: a functional MRI study. NeuroImage 16:389-400.

Sathian K (2000) Practice makes perfect-sharper tactile perception in the blind. Neurology 54:2203-2204.

Sathian K, Zangaladze A (2001) Feeling with the mind's eye: the role of visual imagery in tactile perception. Opt Vis Sci 78:276-281.

Seger CA, Rabin LA, Desmond JE, Gabrieli JD (1999) Verb generation priming involves conceptual implicit memory. Brain Cogn 41:150-177.

Sereno MI, Dale AM, Reppas JB, Kwong KK, Belliveau JW, Brady TJ, Rosen BR, Tootell RB (1995) Borders of multiple visual areas in humans revealed by functional magnetic resonance imaging. Science 268:889-893.

Snyder A, Shapley R (1979) Deficits in the visual evoked potentials of cats as a result of visual deprivation. Exp Brain Res 37:73-86.

Stevens J, Foulke E, Patterson M (1996) Tactile acuity, aging, and Braille reading in long-term blindness. J Exp Psych Appl 2:91-106.

Tagamets MA, Novick JM, Chalmers ML, Friedman RB (2000) A parametric approach to orthographic processing in the brain: an fMRI study. J Cognit Neurosci 12:281-297.

Thompson WL, Kosslyn SM, Sukel KE, Alpert NM (2001) Mental imagery of high- and low-resolution gratings activates area 17. NeuroImage 14:454-464.

Tootell RB, Reppas JB, Kwong KK, Malach R, Born RT, Brady TJ, Rosen BR Belliveau JW (1995) Functional analysis of human MT and related visual cortical areas using magnetic resonance imaging. J Neurosci 15:3215-3230.

Tootell RB, Dale AM, Sereno MI, Malach R (1996) New images from human visual cortex. Trends Neurosci 19:481-489.

Tootell RB, Mendola JD, Hadjikhani NK, Ledden PJ, Liu AK, Reppas JB, Sereno MI, Dale AM (1997) Functional analysis of V3A and related areas in human visual cortex. J Neurosci 17:7060-7078.

Tootell RB, Hadjikhani N, Hall EK, Marrett S, Vanduffel W, Vaughan JT, Dale AM (1998) The retinotopy of visual spatial attention. Neuron 21:1409-1422.

Van Boven RW, Hamilton RH, Kauffman T, Keenan JP, Pascual-Leone A (2000) Tactile spatial resolution in blind Braille readers. Neurology 54:2230-2236

Van Essen D, Drury H, Joshi S, Miller M (1998) Functional and structural mapping of human cerebral cortex: solutions are in the surfaces. Proc Natl Acad Sci USA 95:788-795.

Van Essen DC (2002) Windows on the brain. The emerging role of atlases and databases in neuroscience. Curr Opin Neurobiol 12:574-579.

Van Essen DC (2003) Organization of visual areas in macaque and human cerebral cortex. In: The visual neurosciences (Chalupa L, Werner J, eds). Boston: MIT Press, in press.

Wanet-Defalque MC, Veraart C, De Volder A, Metz R, Michel C, Dooms G, Goffinet A (1988) High metabolic activity in the visual cortex of early blind human subjects. Brain Res 446:369-373.

Weeks R, Horwitz B, Aziz-Sultan A, Tian B, Wessinger CM, Cohen LG, Hallett M, Rauschecker JP (2000) A positron emission tomographic study of auditory localization in the congenitally blind. J Neurosci 20:2664-2672.

Zangaladze A, Epstein CM, Grafton ST, Sathian K (1999) Involvement of visual cortex in tactile discrimination of orientation. Nature 401:587-590.

Zatorre RJ (2001) Do you see what I'm saying? Interactions between auditory and visual cortices in cochlear implant users. Neuron 31:13-14. 